pH-Dependent Morphology and Photoresponse of Azopyridine-Terminated Poly(N-isopropylacrylamide) Nanoparticles in Water

\title{
Ren, Hao
}

2019-04-23

Ren , H , Quu , X-P , Shi , Y , Yang , P \& Winnik , F M 2019 , ' pH-Dependent Morphology and Photoresponse of Azopyridine-Terminated Poly(N-isopropylacrylamide) Nanoparticles in Water ' , Macromolecules , vol. 52 , no. 8 , pp. 2939-2948 . https://doi.org/10.1021/acs.macromol.9b00193

http://hdl.handle.net/10138/314247

https://doi.org/10.1021/acs.macromol.9b00193

cc_by_nc

acceptedVersion

Downloaded from Helda, University of Helsinki institutional repository.

This is an electronic reprint of the original article.

This reprint may differ from the original in pagination and typographic detail.

Please cite the original version. 


\title{
pH-Dependent morphology and photoresponse of azopyridine-terminated poly(N-isopropylacrylamide) nanoparticles in water
}

\author{
Hao Ren, ${ }^{a}$ Xing-Ping Qiu, ${ }^{b}$ Yan Shi, ${ }^{c}$ Peng Yang, ${ }^{a}$ Françoise M. Winnik $* d$ \\ ${ }^{a}$ School of Chemistry and Chemical Engineering, Shaanxi Normal University, Xi'an 710062, P. R. \\ China. \\ b Department of Chemistry, University of Montreal, CP 6128 Succursale Centre Ville, Montreal, \\ QC, H3C 3J7, Canada. \\ ${ }^{c}$ School of Materials Science and Engineering, Beijing University of Chemical Technology, Beijing \\ 100029, P. R. China. \\ ${ }^{\mathrm{d}}$ Laboratory of Polymer Chemistry, Department of Chemistry, PB 55, University of Helsinki, \\ Helsinki FI00140 Finland \\ *corresponding author \\ E-mail: francoise.winnik@helsinki.fi
}

\begin{abstract}
A series of azopyridine-terminated poly(N-isopropylacrylamide)s (C12-PN-AzPy), $(\sim 5,000<$ $\mathrm{M}_{\mathrm{w}}<20,000 \mathrm{~g} \mathrm{~mol}^{-1}$, PDI 1.25 or less) was prepared by reversible addition-fragmentation chain transfer (RAFT) polymerization of NIPAM in the presence of a chain transfer agent that contains an AzPy group and an $n$-dodecyl chain. $\quad$ In cold water, the polymers form nanoparticles $(5.9 \mathrm{~nm}<$ $\mathrm{R}_{\mathrm{h}}<10.9 \mathrm{~nm}$ ) that were characterized by light scattering (LS), ${ }^{1} \mathrm{H}$ NMR diffusion experiments, and
\end{abstract}


high-resolution transmission electron microscopy (HR-TEM). We monitored the pH-dependent photo-isomerization of C12-PN-AzPy nanoparticles by steady-state and time-resolved UV-Vis absorption spectroscopy. Azopyridine is known to undergo a very fast cis-to-trans thermal relaxation when the azopyridine nitrogen is quaternized or bound to a hydrogen bond donor. The cis to trans thermal relaxation of the AzPy chromophore in acidic nanoparticles suspension is very fast with a half-life $\tau=2.3 \mathrm{~ms}$ at $\mathrm{pH} 3.0$. It slows down slightly for nanoparticles in neutral water $(\tau=$ $0.96 \mathrm{~s}, \mathrm{pH} 7.0)$, and it is very slow for AzPy-PNIPAM particles in alkaline medium ( $\tau>3600 \mathrm{~s}, \mathrm{pH}$ 10). The pH-dependent dynamics of the cis-to-trans dark relaxation, supported by FTIR spectroscopy, ${ }^{1} \mathrm{H}$ NMR spectroscopy, and LS analysis, suggest that in acidic medium, the nanoparticles consist of a core of assembled C12 chains surrounded by a shell of hydrated PNIPAM chains with the $\mathrm{AzPy}^{+}$end groups preferentially located near the particle/water interface. In neutral medium, the shell surrounding the core contains AzPy groups H-bonded to the amide hydrogen of the PNIPAM chains repeat units. At $\mathrm{pH} \mathrm{10.00,} \mathrm{the} \mathrm{amide} \mathrm{hydrogen} \mathrm{binds} \mathrm{preferentially} \mathrm{to} \mathrm{the}$ hydroxide anions. The AzPy groups reside preferentially in the vicinity of the C-12 core of the nanoparticles. The morphology of the nanoparticles results from the competition between the segregation of the hydrophobic and hydrophilic components and weak attractive interactions, such as H-bonds between the AzPy groups and the amide hydrogen of the PNIPAM repeat unit.

\section{Introduction}

Among the various stimuli for responsive polymer-based devices, light possesses several advantages: it is directional, tunable in terms of energy, and it can be turned on and off rapidly. ${ }^{1-3}$ Azobenzene, which undergoes reversible trans to cis photoisomerization, is commonly used for such applications. The trans-to-cis isomerization requires UV light irradiation. The cis to trans back conversion occurs upon irradiation with visible light and also by thermal relaxation in the dark. ${ }^{4,5}$ The thermal cis-to-trans relaxation of azobenzene is very slow. It takes several hours for completion. Disubstituted azobenzenes, such as 4-N,N-dimethylamino-4'-nitro-azobenzene, undergo thermal cis to trans isomerization much faster, with relaxation times on the order $10-100 \mu s^{6,7}$ The fast response results from the "push-pull" electronic distribution imposed by the electron donor and the 
electron withdrawing substituents linked, respectively, to the 4 and 4' positions. This speed is critical for applications that require real time information without the use of a second photostimulation to regenerate the trans form, an important thrust in current material science.

Replacement of one phenyl ring of azobenzene with a pyridinium ring has a similar effect on the $\pi$-electron distribution of azo chromophores, as exemplified by azopyridinium methyl iodide for which the cis-to-trans thermal relaxation time is on the order of 10 to $100 \mu$ s. ${ }^{6}$ The pyridine ring nitrogen is a powerful $\mathrm{H}$-bond acceptor ${ }^{8}$, a property employed extensively in the construction of supermolecular assemblies, such as liquid crystals ${ }^{9-11}$, metal-organic frameworks ${ }^{12,13}$, fibers ${ }^{14}$, films ${ }^{15,16}$, and gels ${ }^{17-19}$. It turns out that binding of the AzPy nitrogen to common H-bond donors, such as phenols, accelerates the cis-to trans thermal relaxation rate of neutral AzPy due to the redistribution of the AzPy $\pi$-electron imposed by the H-bond formation. This effect was exploited recently by Gelebart et al. who succeeded in generating continuous, macroscopic mechanical waves by continuous irradiation of films containing AzPy H-bonded to benzoic acid moieties. ${ }^{16}$

In spite of such spectacular achievements, the design of simple, easily controllable, and fastrelaxing azo systems remains challenging, particularly in the case of water-borne polymeric materials. ${ }^{20,}{ }^{21}$ Amphiphilic copolymers containing AzPy have been reported and evaluated in solutions, micro-, and nanoparticles in suspensions, or as hydrogels, ${ }^{22,23}$ For instance, Zhang et al. reported AzPy-containing PNIPAM block copolymers in water form of giant vesicles, which undergo photo-controlled swelling and shrinking. ${ }^{17-19}$ Supramolecular hydrogels formed by coassembly of phenylalanine-based amphiphiles and AzPy moieties were shown to undergo macroscopic gel-sol transition in response to light, and also through changes in temperature, or $\mathrm{pH}$. ${ }^{24}$ The dynamics of the thermal cis-trans relaxation were not assessed in these studies.

We report here the preparation of amphiphilic poly(N-isopropylacrylamides) (PNIPAM) bearing an AzPy moiety on one chain end and an $n$-dodecyl group on the other end, as simple models to evaluate the dynamics of neutral and charged AzPy in aqueous environments. A series of polymers (C12-PN-AzPy) of well-defined molar mass were synthesized by RAFT polymerization using a chain transfer agent bearing AzPy and $n$-dodecyl groups (Scheme 1). Light scattering measurements, ${ }^{1} \mathrm{H}$ NMR spectroscopy diffusion and fluorescence probe studies indicate that the polymers self-assemble in neutral water to form colloidally-stable nanoparticles. The photophysical 
properties of the colloidal dispersions were monitored as a function of the dispersions $\mathrm{pH}$. Transient absorption spectroscopy measurements indicated that the cis to trans thermal relaxation of $\mathrm{AzPy}$ is sluggish in alkaline dispersions of C12-PN-AzPy, but extremely fast in acidic and, unexpectedly, in neutral dispersions of the polymer. The fast dynamics of the cis-to-trans dark relaxation exhibited by neutral C12-PN-AzPy suggest that the AzPy end-groups form H-bonds with amide hydrogens of the PNIPAM repeat units in neutral conditions. This hypothesis was confirmed by several control measurements. It led us to conclude that C12-PN-AzPy chains do not form typical core-shell flower micelles, but adopt a more complex morphology that varies depending on the solution $\mathrm{pH}$. This result is of interest in the context of polymer self-assembly and also from the practical view point as an entry to fast responsive light-driven systems.

\section{Experimental section}

\subsection{Materials}

$\mathrm{N}$-isopropylacrylamide was purchased from Sigma-Aldrich and recrystallized from hexane. The initiator 4,4'-Azobis(4-cyanovaleric acid) (ACPA, 97\%) was purchased from Sigma-Aldrich and recrystallized from methanol. The RAFT agent $S^{\prime}$-1-dodecyl-S'-( $\alpha, \alpha^{\prime}$-dimethyl- $\alpha$ "-acetic acid)

trithiocarbonate (CTA-1) was synthesized as described earlier. ${ }^{25}$ 2-(4-(Pyridin-4yldiazenyl)phenoxy)ethan-1-ol (HO-C2-AzPy) and 2-(4-(phenyldiazenyl)phenoxy)ethan-1-ol (HO$\mathrm{C}_{2}$-Azo) were synthesized following known procedures. ${ }^{26,27}$ All other reagents were obtained from Sigma-Aldrich and were used as received.

\subsection{Synthesis of the RAFT agents CTA-AzPy and CTA-Azo (see Scheme S1.)}

\section{2-(4-(pyridin-4-yldiazenyl)phenoxy)ethyl 2-(((dodecylthio)carbonothioyl)thio)-}

2-methylpropanoate (CTA-AzPy) A solution of dicyclohexylcarbodiimide (DCC, $0.66 \mathrm{~g}, 3.2 \mathrm{mmol}$ ) in $\mathrm{CH}_{2} \mathrm{Cl}_{2}(10 \mathrm{~mL})$ was added dropwise to a solution of 2-(dodecylthiocarbonothioylthio)-2methylpropionic acid (CTA-1, $1.0 \mathrm{~g}, 2.8 \mathrm{mmol}$ ) and 2-(4-(pyridin-4-yldiazenyl)phenoxy)ethan-1- 
ol (HO-C2-AzPy, $0.68 \mathrm{~g}, 2.8 \mathrm{mmol})$ in $\mathrm{CH}_{2} \mathrm{Cl}_{2}(20 \mathrm{~mL}) \mathrm{kept}$ in an ice/water bath. After 12 hours at rt. the solid was removed by filtration, and the solvent was stripped off by evaporation. The solid residue was purified by chromatography over a silica column eluted with hexane/ethyl acetate (4/1, v/v) as eluent. A yellow solid (1.2 g, yield $72 \%$ ) was obtained. ${ }^{1} \mathrm{H} \mathrm{NMR}\left(\mathrm{CDCl}_{3}\right): \delta 8.79(\mathrm{~d}, \mathrm{~J}=8.0$ $\mathrm{Hz}, 2 \mathrm{H}), \delta 7.96(\mathrm{~d}, \mathrm{~J}=8.0 \mathrm{~Hz}, 2 \mathrm{H}), \delta 7.68(\mathrm{~d}, \mathrm{~J}=8.0 \mathrm{~Hz}, 2 \mathrm{H}), \delta 7.03(\mathrm{~d}, \mathrm{~J}=8.0 \mathrm{~Hz}, 2 \mathrm{H}), \delta 4.51$ (t, $\mathrm{J}=4.0 \mathrm{~Hz}, 2 \mathrm{H}), \delta 4.27(\mathrm{t}, \mathrm{J}=4.0 \mathrm{~Hz}, 2 \mathrm{H}), \delta 3.14(\mathrm{t}, \mathrm{J}=8.0 \mathrm{~Hz}, 2 \mathrm{H}), \delta 1.71(\mathrm{~s}, 6 \mathrm{H}), \delta 1.58(\mathrm{~m}, 2 \mathrm{H}), \delta$ $1.22(\mathrm{br}, 20 \mathrm{H}), \delta 0.88(\mathrm{t}, \mathrm{J}=6.5 \mathrm{~Hz}, 3 \mathrm{H})$. (Figure S1) The ${ }^{13} \mathrm{C}$ NMR and the Heteronuclear Multiple Quantum Correlation (2D-HMQC) spectra of CTA-AzPy are shown in Figures S2 and S3. The mass spectrum is given in Figure S4.

\section{2-(4-(phenyldiazenyl)phenoxy)ethyl 2-(((dodecylthio)carbonothioyl)thio)- 2-methylpropanoate (CTA-Azo)}

A solution of dicyclohexylcarbodiimide (DCC, $0.66 \mathrm{~g}, 3.2 \mathrm{mmol}$ ) in $\mathrm{CH}_{2} \mathrm{Cl}_{2}(10 \mathrm{~mL}$ ) was added dropwise to a solution of CTA-1 (1.0 g, $2.8 \mathrm{mmol})$ and 2-(4-(phenyldiazenyl) phenoxy) ethan-1-ol (HO-C 2 -Azo, $0.67 \mathrm{~g}, 2.8 \mathrm{mmol}$ ) in $\mathrm{CH}_{2} \mathrm{Cl}_{2}(20 \mathrm{~mL})$ kept in an ice/water bath. After 12 hours at r.t. The solid was removed by filtration. The filtrate was evaporated to dryness. The solid residue was purified by chromatography over a silica column eluted with hexane/ethyl acetate $(4 / 1, \mathrm{v} / \mathrm{v})$ as eluent. An orange solid (1.1 g, yield 65\%) was obtained. ${ }^{1} \mathrm{H}$ NMR $\left(\mathrm{CDCl}_{3}\right) \delta 7.93(\mathrm{~m}, 4 \mathrm{H}), \delta 7.52(\mathrm{~m}, 3 \mathrm{H})$, $\delta 7.03(\mathrm{~d}, \mathrm{~J}=12.0 \mathrm{~Hz}, 3 \mathrm{H}), \delta 4.53$ (t, J=4.8 Hz, 2H), $\delta 4.27$ (t, J=4.8 Hz, 2H), $\delta 3.16$ (t, J=8.0 Hz, 2H), $\delta 1.73(\mathrm{~s}, 6 \mathrm{H}), \delta 1.60(\mathrm{~m}, 2 \mathrm{H}), \delta 1.24(\mathrm{br}, 20 \mathrm{H}), \delta 0.90(\mathrm{t}, \mathrm{J}=6.8 \mathrm{~Hz}, 3 \mathrm{H})$. (Figure S1).

\subsection{General procedure for the synthesis of end-functionalized PNIPAMs}

The polymers were prepared by RAFT polymerization of NIPAM in the presence of either CTAAzPy or CTA-Azo. The following procedure leading to C12-PN-AzPy $12 \mathrm{~K}$ is typical. In a $50 \mathrm{~mL}$ flask, NIPAM (1.13 g, $10 \mathrm{mmol})$, the CTA-AzPy (0.589 g, $1.0 \mathrm{mmol})$ and 4,4'-azobis(4-cyanovaleric acid) (ACPA, 0.056g, $0.2 \mathrm{mmol})$ were dissolved in 1,4 dioxane $(10 \mathrm{~mL}) .1,3,5$-Trioxane $(0.02 \mathrm{~g})$ was added to the solution as an internal reference for ${ }^{1} \mathrm{H}$ NMR measurements monitoring the progress of the polymerization. The solution was degassed with nitrogen for $30 \mathrm{~min}$ at room temperature. The flask was placed in a preheated oil bath set at $80^{\circ} \mathrm{C}$ and kept at this temperature for 6 hours. The polymerization mixture was cooled to room temperature, and the polymer was 
purified by three consecutive precipitations into hexane. The sample was further purified by dialysis against water for 3 days and isolated by freeze-drying. See Figures $\mathbf{S 5}$ and $\mathbf{S 6}$ for the ${ }^{1} \mathrm{H}$ NMR spectra of C12-PN-AzPy and C12-PN-Azo.

\subsection{Quaternization of the azopyridium end group of AzPy-terminated PNIPAM}

Iodoethane $(0.5 \mathrm{~mL}, 6.25 \mathrm{mmol})$ was added to a solution of C12-PN-AzPy $12 \mathrm{~K}(0.45 \mathrm{~g})$ in $\mathrm{CH}_{2} \mathrm{Cl}_{2}$ $(10 \mathrm{~mL})$. The reaction mixture was refluxed at $40{ }^{\circ} \mathrm{C}$ for five days, while monitoring the degree of advancement of the reaction by ${ }^{1} \mathrm{H}$ NMR spectroscopy. After completion of the reaction, the solvent was removed by evaporation. The polymer was dissolved in methanol, dialyzed against water for 3 days and isolated by freeze-drying $(0.56 \mathrm{~g})$ as an orange powder. See Figures $\mathbf{S} 7$ for the ${ }^{1} \mathrm{H}$ NMR spectra of the region part of C12-PN-AzPy $12 \mathrm{~K}$ and C12-PN-AzPyC ${ }_{2} \mathrm{H}_{5}{ }^{+} 12 \mathrm{~K}$.

\subsection{Characterization}

\section{Instrumentation}

${ }^{1} \mathrm{H}$ NMR spectra were recorded on a Bruker AMX-400 (400 MHz) spectrometer. NMR diffusion experiments were performed with a Bruker Avance III $(500 \mathrm{MHz})$ at $10^{\circ} \mathrm{C}$. Molecular weights and molecular weight distributions were determined with an Agilent 1100 gel permeation chromatography (GPC) system fitted with a TSK-gel R-M column (particle size $13 \mu \mathrm{m}$, exclusion limit $1 \times 10^{7} \mathrm{Da}$ for polystyrene in DMF) and a TSKgel R-3000 column (particle size $7 \mu \mathrm{m}$, exclusion limit $1 \times 10^{5} \mathrm{Da}$ for polystyrene in DMF) (Tosoh Biosep; DMF containing $0.4 \mathrm{wt} \% \mathrm{LiBr}$ was used as eluent and the flow rate was set at $0.5 \mathrm{~mL} / \mathrm{min}$; the column temperature was set at $40^{\circ} \mathrm{C}$. Mass spectra were acquired on an Agilent 6224 Accurate-Mass TOF LC/MS. Fourier Transform Infrared Spectra (FT-IR) were recorded on a Nicolet 8700 FTIR spectrometer. Critical assembly concentration (CAC) values determined by a fluorescence probe were conducted with a Varian fluorimeter (Agilent Technologies).

\section{Determination of the polymers molar mass from UV-Vis absorption data}

The molecular weight was determined according to Eq 1:

$$
M_{n}=\frac{w}{c_{C T A}}
$$

Eq 1

where $w$ is the weight of polymer in the solution (in g), сстA is the amount of RAFT agent residues 
(end-groups of the polymer) in solution (in mol), determined experimentally by application of Beer's law. Gaussian functions were used to separate the overlapping absorbances of the trithiocarbonate, azopyridine and azobenzene chromophores (fitting from $270 \mathrm{~nm}$ to $450 \mathrm{~nm}$ ). The molar extinction coefficients of the trithiocarbonate and either the azopyridine, or the azobenzene chromophores in methanol are $\varepsilon 310 \mathrm{~nm}=20400 \mathrm{~L} \mathrm{~mol}^{-1} \mathrm{~cm}^{-1}, \varepsilon 355 \mathrm{~nm}=24700 \mathrm{~L} \mathrm{~mol}^{-}$ ${ }^{1} \mathrm{~cm}^{-1}$, and $\varepsilon 351 \mathrm{~nm}=18700 \mathrm{~L} \mathrm{~mol}^{-1} \mathrm{~cm}^{-1}$, respectively.

\section{Solution preparation.}

For light scattering experiments, polymer solutions were prepared by dissolution in water of a suitable weighed amount of polymer. Solutions were refrigerated $\left(\sim 5^{\circ} \mathrm{C}\right)$ for at least $24 \mathrm{~h}$ before analysis to ensure complete polymer dissolution. For the $\mathrm{pH}$ dependent-tests the solution $\mathrm{pH}$ was adjusted by dropwise addition of $0.1 \mathrm{M} \mathrm{NaOH}$ or $0.1 \mathrm{M} \mathrm{HCl}$ to neutral polymer solutions. Solutions were refrigerated at least $24 \mathrm{~h}$ before testing.

\section{Critical aggregation concentration (CAC) of polymeric micelles}

The CAC of the modified PNIPAM samples was determined with Nile Red (NR) as fluorescence probe. Solutions for analysis were prepared as follows. A drop of a concentrated NR solution in ethanol was placed in a vial and the solvent was evaporated with a flow of nitrogen. Aqueous polymer solutions ranging in concentration from 0.001 to $5.0 \mathrm{mg} / \mathrm{mL}$ were prepared by dilution with water of a polymer stock solution $(5.0 \mathrm{mg} / \mathrm{mL})$. The solutions were placed in the vials containing $\mathrm{NR}$ and refrigerated for at least $24 \mathrm{~h}$ before measurement. The excitation wavelength was set at 520 $\mathrm{nm}$, and both the excitation and emission slits were set at $5 \mathrm{~nm}$. The CAC values were determined by two methods for accuracy, one is the inflection point of plots of the fluorescence maximum wavelength versus the logarithm of the polymer concentration, and another one is the onset of the increase of the fluorescence intensity at $630 \mathrm{~nm}$ versus the logarithm of the polymer concentration.

\section{Light scattering (LS) Measurements}

Dynamic light scattering (DLS) and Static light scattering (SLS) studies were carried out with a light scattering system equipped with a CGS-3 goniometer (ALV GmbH) fitted with an ALV/LSE5003 multiple correlator (ALV GmbH) and a C25P temperature controller (Thermo Haake). The light source was a He-Ne laser $(632 \mathrm{~nm})$. Polymer solutions in water were refrigerated overnight and filtered through a $0.2 \mu \mathrm{m}$ Millex Millipore PVDF filter prior to analysis. 
In SLS experiments, the scattering intensity was measured at several angles from $30-150^{\circ}$ against a toluene standard. The time averaged excess scattered intensity at angle $\theta$, also known as the Rayleigh ratio $\mathrm{R}_{\mathrm{vv}}(\mathrm{q})$, was related to the weight-averaged molar mass $\mathrm{M}_{\mathrm{w}}$, the Z-averaged root mean square radius $\mathrm{R}_{\mathrm{g}}$, the second virial coefficient $\mathrm{A}_{2}$ and the scattering vector $(\mathrm{q})$, where $\mathrm{K}=$ $4 \pi^{2} \mathrm{n}^{2}(\mathrm{dn} / \mathrm{dc})^{2} /\left(\mathrm{N}_{\mathrm{A}} \lambda_{0}{ }^{4}\right)$ and $\mathrm{q}=\left(4 \pi \mathrm{n} / \lambda_{0}\right) \sin (\theta / 2)$, with $\mathrm{N}_{\mathrm{A}}, \mathrm{n},(\mathrm{dn} / \mathrm{dc})$ and $\lambda_{0}$ being Avogadro's constant, the refractive index of the solvent, the specific refractive index increment of the solution, and the wavelength of light in vacuum, respectively. The $\mathrm{dn} / \mathrm{dc}$ value of PNIPAM in water was assumed to be independent of temperature and equal to $0.167 \mathrm{~mL} / \mathrm{g} .{ }^{28}$ The partial Zimm plot and the aggregation number, $\mathrm{N}_{\text {agg }}$ for aggregates were obtained from equations 2 and 3:

$$
\begin{gathered}
\frac{K c}{R_{\mathrm{vv}}(q)} \approx \frac{1}{M_{w}}\left(1+\frac{1}{3} R_{g}{ }^{2} q^{2}\right)+2 A_{2} C \\
N_{\text {agg }}=\frac{M_{\text {w.micelle }}}{M_{\text {w.polymer }}}
\end{gathered}
$$

For Dynamic light scattering (DLS), the $\mathrm{g}^{2}(\mathrm{q}, \mathrm{t})$ autocorrelation functions from DLS analysis for each angle were analyzed by the CONTIN algorithm to determine the relaxation time, $\Gamma$. The $\Gamma$ values at each angle were plotted against the square of the scattering wave vector (q), and the diffusion coefficient (D) was calculated from $\mathrm{D}=\left(\Gamma / \mathrm{q}^{2}\right)_{\mathrm{q} \rightarrow 0}$. The hydrodynamic radius $\left(\mathrm{R}_{\mathrm{h}}\right)$ is given by the Stokes-Einstein equation, $R_{h}=k_{B} T /(6 \pi \eta D)$, where $k_{B}$ is the Boltzmann constant, $T$ is the absolute temperature and $\eta$ is the solvent viscosity.

\section{NMR diffusion measurements}

Diffusion experiments were carried out with a Bruker Avance 500 NMR spectrometer operating at the amplitude $g$ of the pulsed field gradients stepped up linearly from 15 to $300 \mathrm{G} \mathrm{cm}^{-1}$ in 16 steps using a stimulated echo sequence with gradient pulses of a length of $\delta=2 \mathrm{~ms}$. The total diffusion time was $\Delta=100 \mathrm{~ms}$.

Polymer diffusion coefficients (D) were obtained by fitting to a Gaussian decay, see equation 4:

$$
\frac{s}{S_{0}}=\exp \left[-\gamma^{2} \delta^{2} g^{2} D\left(\Delta-\frac{\delta}{3}\right)\right]
$$

where $S$ and $S_{0}$ are the integral intensities with and without gradient, which were calculated from the resonance of the $-\mathrm{CH}_{3}$ protons ( $\delta: 0.621$ to $1.153 \mathrm{ppm}$ ); $\gamma$ is the magnetogyric ratio. $(4.258 \times$ $10^{3} \mathrm{~Hz} / \mathrm{G}$ in this case), and $\mathrm{g}$ is the amplitude of the magnetic field gradient $\left(17.8125 \mathrm{G} \mathrm{cm}^{-1} / \mathrm{step}\right.$ 
in this case). The operating temperature was $10{ }^{\circ} \mathrm{C}$. All polymer solutions $\left(1.0 \mathrm{mg} / \mathrm{mL}\right.$ in $\left.\mathrm{D}_{2} \mathrm{O}\right)$ were refrigerated for at least 24 hours prior to measurements

\section{Irradiation experiments}

Photoisomerization tests were carried out with a Prizmatix LED light source emitting at a wavelength of $365 \mathrm{~nm}(50 \mathrm{~mW})$. The photoisomerization measurements were conducted at $15{ }^{\circ} \mathrm{C}$ for all samples. A polymer solution $(2 \mathrm{~mL})$ was placed in a $10-\mathrm{mm}$ cuvette and irradiated. Absorbance spectra of the sample were measured as a function of irradiation time.

\section{Thermal relaxation kinetics.}

The relaxation of azopyridine group under neutral conditions was determined with a UV-vis spectrometer (Lambda 750, PerkinElmer) at r.t. A $365 \mathrm{~nm}$ LED-UV lamp holder was placed above the solution kept in the dark prior to irradiation. The changes with time of the absorbance intensity at $355 \mathrm{~nm}$ were recorded upon UV irradiation until the initial intensity value was recovered. The time interval between each measurement was set at $0.2 \mathrm{~s}$. The relaxation kinetics were fitted with the stretched exponential function defined in Eq 5 and 6: ${ }^{29}$

$$
\begin{gathered}
\mathrm{A}(\mathrm{t})=A_{\infty}-\left(A_{\infty}-A_{0}\right) e^{-(k t)^{\beta}} \\
\tau=\sqrt[\beta]{\ln (2) / k}
\end{gathered}
$$

where $\mathrm{k}$ is the fitting constant; $\beta$ the stretched exponential parameter; $\tau$ the half-life of cisazopyridine; $\mathrm{A} 0, \mathrm{~A}(\mathrm{t})$, and $\mathrm{A}_{\infty}$ are the absorbances at $355 \mathrm{~nm}$ before $\mathrm{UV}$ irradiation, after $\mathrm{UV}$ irradiation at time $\mathrm{t}$, and in the photostationary state, respectively.

\section{Transient absorption measurements}

The relaxation rate of the N-ethyl cis-azopyridinium moiety in $\mathrm{C} 12-\mathrm{PN}_{-} \mathrm{AzPyC}_{2} \mathrm{H}_{5}{ }^{+}(12 \mathrm{~K})$ was measured at room temperature with a laser flash photolysis system (LP 920, Edinburgh Instruments). The laser wavelength was $355 \mathrm{~nm}$. The pulse time was $10 \mathrm{~ns}$ with an energy of $10 \mathrm{~mJ} /$ pulse. The detection wavelength was $365 \mathrm{~nm}$. The data was fit with the exponential function defined in Eq 7 :

$$
\Delta \mathrm{OD}(\mathrm{t})=\Delta \mathrm{OD}_{0} \exp [-t / \tau]
$$

where $\Delta \mathrm{OD}_{0}$ is the initial optical density, $\tau$ is the relaxation time; $\Delta \mathrm{OD}$ is the time dependent optical density.

\section{Transmission electron microscopy (TEM) measurements.}

TEM images were recorded with a Tecnai G2 F20 at 200KV (FEI, USA), equipped with a 4k CCD 
camera. An aqueous solution of C12-PN-AzPy 20K $\left(0.5 \mathrm{mg} \mathrm{mL}^{-1}\right)$ was kept at $5{ }^{\circ} \mathrm{C}$ for at least 24 hours. One drop of the cold solution was deposited on a carbon-coated copper grid placed on a filter paper. The prepared TEM grid was dried at r.t. under vacuum before measurement.

\section{Results and discussion}

\subsection{Synthesis and characterization of end-modified PNIPAM derivatives}

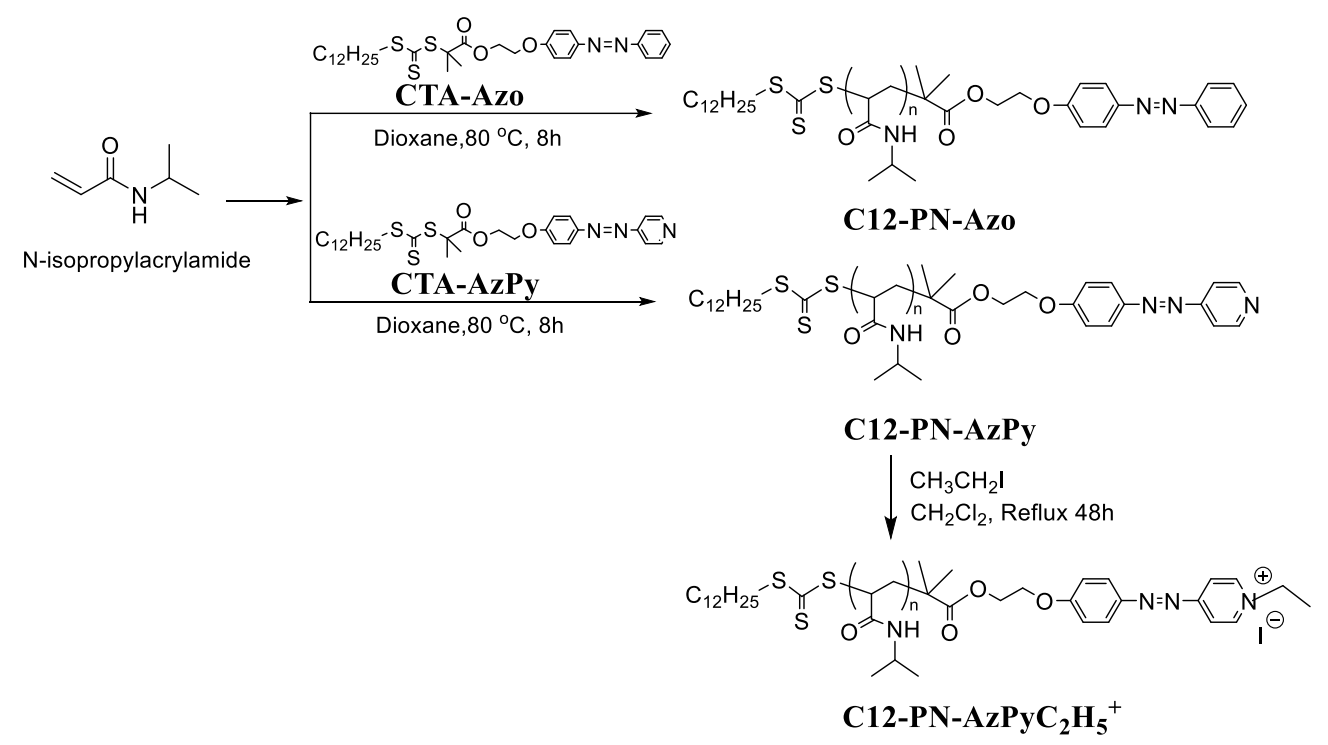

Scheme 1. Synthetic pathways to $\alpha$-azobenzene-, $\alpha$-azopyridine-, and $\alpha$-ethyl-azopyridinium$\omega$ - $n$-dodecyl-PNIPAMs.

The polymers were prepared by RAFT polymerization of NIPAM in dioxane using the chain transfer agents CTA-AzPy or CTA-Azo, the latter CTA leading to azobenzene-modified PNIPAM used in control experiments described below (Scheme 1). The structure of the two CTAs was confirmed by their ${ }^{1} \mathrm{H}$ NMR, ${ }^{13} \mathrm{C}$ NMR, and 2D-HMQC NMR spectra, shown in Figure S1-3 and their purity was ascertained by high-resolution mass spectrometry (Figure S4). By changing the NIPAM to CTA-AzPy molar ratio in the polymerization mixture, we obtained five samples of C12PN-AzPy ranging in molar mass from 5,000 to $20,000 \mathrm{~g} / \mathrm{mol}$. The successful incorporation of the hydrophobic C12 group on one end of the polymer chains and of the AzPy group on the other was confirmed by the ${ }^{1} \mathrm{H}$ NMR and UV-vis absorption spectra of the polymers. Figure 1a presents the ${ }^{1} \mathrm{H}$ NMR spectrum of $\mathrm{C} 12-\mathrm{PN}-\mathrm{AzPy}-12 \mathrm{~K}$ in $\mathrm{CDCl}_{3}$. It features a triplet at $0.88 \mathrm{ppm}$, ascribed to the 
resonance of the terminal methyl protons of the dodecyl chain, and signals in the aromatic spectral region ascribed to the azopyridine protons: signals $\mathbf{a}$ and $\mathbf{b}$ are attributed to the protons of the pyridine ring while the signals $\mathbf{c}$ and $\mathbf{d}$ correspond to the protons of the aromatic ring connected to the polymer by an ether bond. The presence of the trithiocarbonate function on the $\omega$-end of the polymer is confirmed by the polymer UV-vis absorption spectrum, which features a band centered at $310 \mathrm{~nm}$, attributed to the trithiocarbonate, in addition to a band at $355 \mathrm{~nm}$ ascribed to the AzPy chromophore linked the $\alpha$-end (Figure S9b). The azopyridine group was quaternized by reaction of C12-PN-AzPy with ethyl iodide. The structure of the resulting polymer, C12-PN-AzPyC $\mathrm{CH}_{5}{ }^{+}$, was confirmed by its ${ }^{1} \mathrm{H}$ NMR spectrum, see Figure $\mathbf{1 b}$. The aromatic signals of the spectrum of C12PN-AzPy underwent a downfield shift upon quaternization of the pyridine ring, as expected in view of the strong electron-withdrawing effect of the pyridinium ring. ${ }^{30}$ Signals characteristic of the azopyridine protons cannot be detected in the spectrum of the quaternized compound, a good indication that the quaternization went to near completion.

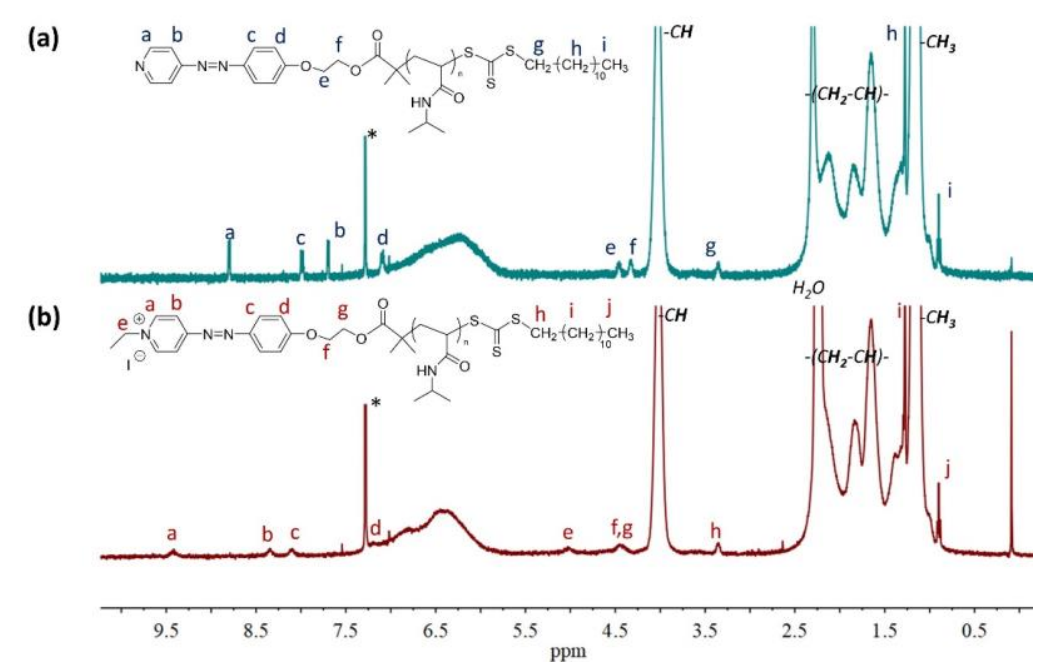

Figure 1. ${ }^{1} \mathrm{H}$ NMR spectra and spectral assignments of (a), C12-PN-AzPy $12 \mathrm{~K}$ and (b) C12$\mathrm{PN}-\mathrm{AzPyC}{ }_{2} \mathrm{H}_{5}+12 \mathrm{~K}$. (the residual solvent $\mathrm{CDCl}_{3}$ singlet is marked with *)

The molar mass $\left(\mathrm{M}_{\mathrm{n}}\right)$ of the polymers was determined by GPC with multi-angle light scattering (MALS) detection. The polydispersity index of the polymers also obtained from the GPC data ranges between 1.03 and 1.25 and the degree of polymerization (DP) varies from 32 to 162 . The molar mass values determined from the ratio of the area of the PNIPAM methine (-CH) resonance in their ${ }^{1} \mathrm{H}$ NMR spectrum to that of the signal attributed to the resonance of $\boldsymbol{H}_{\boldsymbol{a}}$ on the azopyridine 
group, using $\mathrm{M}_{\mathrm{n} \text {. NMR }}=\left(2 \times \boldsymbol{I}_{-\boldsymbol{C H}} / \boldsymbol{I}_{\boldsymbol{H} \boldsymbol{a}}\right) \times 113.2+\mathrm{M}_{\mathrm{CTA} \text {-AzPy }}$, as well as the UV-vis absorption derived $\mathrm{M}_{\mathrm{n}}$ values ( see Figure S9 in the case of C12-PN-AzPy, 12K) agree well the GPC-derived values (Table 1).

Table 1. Molar mass and polydispersity index of the polymers prepared

\begin{tabular}{|c|c|c|c|c|c|}
\hline \multirow{2}{*}{ Sample name } & \multicolumn{3}{|c|}{$\mathrm{M}_{\mathrm{n}}(\mathrm{g} / \mathrm{mol})$} & \multirow{2}{*}{$\mathrm{DP}^{*}$} & \multirow{2}{*}{$\mathrm{M}_{\mathrm{w}} / \mathrm{M}_{\mathrm{n}}{ }^{* *}$} \\
\hline & UV & GPC & NMR & & \\
\hline C12-PN-AzPy 5K & 5500 & 5800 & 4200 & 32 & 1.25 \\
\hline C12-PN-AzPy 7K & 7700 & 7800 & 7900 & 60 & 1.03 \\
\hline C12-PN-AzPy 12K & 12400 & 12900 & 10700 & 110 & 1.09 \\
\hline C12-PN-AzPyC ${ }_{2} \mathrm{H}_{5}{ }^{+} 12 \mathrm{~K}$ & - & 12900 & 10700 & 110 & 1.09 \\
\hline C12-PN-AzPy 20K & 19500 & 19700 & 19000 & 162 & 1.03 \\
\hline C12-PN-Azo 12K & 12600 & 13600 & 12500 & 115 & 1.23 \\
\hline
\end{tabular}

*Degree of polymerization from the NMR spectra of polymer solutions in $\mathrm{CDCl}_{3}$; ** Determined by GPC.

\subsection{Solution properties of the polymers in water $\left(10^{\circ} \mathrm{C}\right)$}

Light scattering is a powerful technique to characterize the size and structure of self-assembled amphiphilic PNIPAMs. ${ }^{31,32}$ Dynamic light scattering (DLS) gives information on the hydrodynamic radius $\left(\mathrm{R}_{\mathrm{h}}\right)$ and static light scattering (SLS) provides the radius of gyration $\left(\mathrm{R}_{\mathrm{g}}\right)$ as well as the average molecular weight $\left(\mathrm{M}_{\mathrm{w} . \text { micelle }}\right)$ and aggregation number $\left(\mathrm{N}_{\mathrm{agg}}\right)$ of the micelles. ${ }^{33,34}$ DLS and SLS analyses of C12-PN-AzPy solutions at $10{ }^{\circ} \mathrm{C}$ revealed the presence of nanoparticles. Their size and aggregation characteristics are listed in Table 2.

Table 2. Characteristics of the C12-PN-AzPy nanoparticles in water $\left(10^{\circ} \mathrm{C},{ }^{\mathrm{d}} 10 \mathrm{mg} / \mathrm{mL}\right)$

\begin{tabular}{lcccccc} 
Sample name & $\mathbf{C A C}(\mathbf{g} / \mathbf{L})^{\mathbf{a}}$ & $\mathbf{N}_{\mathbf{a g g}}{ }^{\mathbf{b}}$ & $\mathbf{R}_{\mathbf{g}}(\mathbf{n m})^{\mathbf{b}}$ & $\mathbf{R}_{\mathbf{h}}(\mathbf{n m})^{\mathbf{b}}$ & $\mathbf{R}_{\mathbf{h}}(\mathbf{n m})^{\mathbf{c}}$ & $\mathbf{R}_{\mathbf{g}} / \mathbf{R}_{\mathbf{h}}$ \\
\hline C12-PN-AzPy 5K & $0.002-0.008$ & $19^{*}$ & $9.2^{*}$ & $6.3^{*}$ & 5.9 & 1.46 \\
C12-PN-AzPy 7K & $0.003-0.006$ & $18^{*}$ & $10.2^{*}$ & $7.4^{*}$ & 7.9 & 1.37 \\
C12-PN-AzPy 12K & $0.025-0.032$ & 15 & 15.6 & 10.5 & 8.0 & 1.48 \\
C12-PN-AzPyC ${ }_{2} \mathrm{H}_{5}{ }^{+} 12 \mathrm{~K}$ & $0.037-0.043$ & 13 & 20.0 & 14.0 & 8.6 & 1.43 \\
C12-PN-AzPy 20K & $0.039-0.035$ & 10 & 14.6 & 10.5 & 10.9 & 1.39 \\
C12-PN-Azo 12K & $0.008-0.010$ & 19 & 13.5 & 8.2 & - & 1.64 \\
\hline
\end{tabular}

${ }^{a}$ Determimed from the inflection points of plots of the maximum NR emission wavelength and of the fluorescence emission intensity at $630 \mathrm{~nm}$ versus polymer concentration. ${ }^{\mathrm{b}}$ Determined by DLS; ${ }^{\mathrm{c}}$ Determined by NMR diffusion experiments, ${ }^{\mathrm{d}}$ this temperature is 
below the cloud point of all solutions, as described in a forthcoming article.

* some large aggregates in suspension were removed by filtration prior to measurements

The $R_{h}$ and $R_{g}$ values of the nanoparticles increase with increasing polymer molar mass, in agreement with related previous studies. ${ }^{32,35}$ The aggregation number $\left(\mathrm{N}_{\mathrm{agg}}\right)$ of the nanoparticles, obtained from LS and NMR diffusion experiments (see Figure S10 and Figure S11) decrease with increasing molar mass of the polymers. The structure parameter, $\rho=\mathrm{Rg} / \mathrm{Rh}$, which reflects the mass distribution of the scattering object, is useful to assess the morphology of self-assembled nanoparticles. ${ }^{28,34} \mathrm{The} \mathrm{R}_{\mathrm{g}} / \mathrm{R}_{\mathrm{h}}$ values of all C12-PN-AzPy nanoparticles in water $\left(10^{\circ} \mathrm{C}\right)$ range from 1.37 to 1.48 , a range of values characteristics of random coils and of core/shell particles with a solvated shell. TEM images of dried C12-PN-AzPy suspensions provide further support to the size of the micelles and the formation of core/shell assemblies (Figure 2c, d). The higher contrast of the particles core, visualized by high resolution TEM, suggests that the core contains closely-packed hydrophobic end groups (Figure 2d). The critical aggregation concentration (CAC) of the C12-PNAzPy samples was evaluated by fluorescence spectroscopy using Nile Red (NR). This probe was selected since its absorption window $\left(\lambda_{\max }=520 \mathrm{~nm}\right)$ does not overlap with the absorption spectra of the AzPy and trithiocarbonate chromophores (see Figure S9) ${ }^{35,} 36$ The emission of NR is affected by the polarity of the probe environment: as the polarity of the environment decreases, the excitation and emission spectra of NR shift to shorter wavelengths and the emission intensity increases ${ }^{37,38}$ as shown in Figure 2a in the case of C12-PN-AzPy 12K. Figures $2 \mathbf{b}$ and S12 present the experimental data used to determine the CAC of this polymer in water from the changes with polymer concentration of the NR emission intensity and emission wavelength, respectively. The CAC values of the C12-PN-AzPy samples increase by a factor of 10 with increasing polymer molar mass, within the $5 \mathrm{~kg} / \mathrm{mol}$ to $20 \mathrm{~kg} / \mathrm{mol}$ molar mass range sampled here (Table 2), in agreement with related studies. ${ }^{32}$ 
(a)

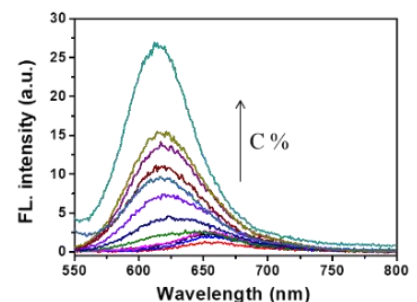

(c)

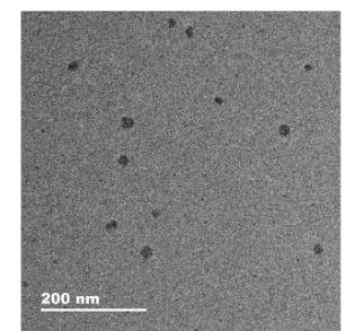

(b)

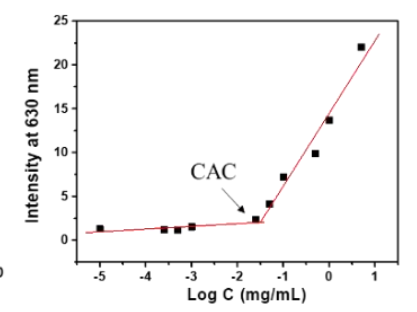

(d)

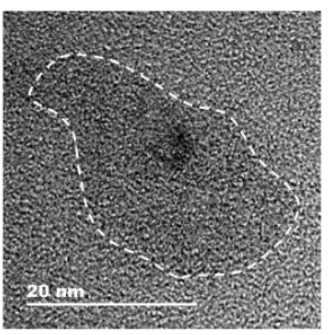

Figure 2. (a). Fluorescence spectra of NR in C12-PN-AzPy $12 \mathrm{~K}$ aqueous solutions of increasing polymer concentration $\left(\lambda_{\mathrm{ex}}=530 \mathrm{~nm}\right.$; slits: $5 \mathrm{~nm}$; temperature, $\left.10^{\circ} \mathrm{C}\right)$. (b). Plot of the NR fluorescence emission intensity at $630 \mathrm{~nm}$ as a function of C12-PN-AzPy $12 \mathrm{~K}$ concentration. (c) TEM images and (d) High resolution electron TEM (HR-TEM) images of C12-PN-AzPy 20K $0.5 \mathrm{mg} / \mathrm{mL}$.

Table 2 also presents the size of nanoparticles obtained for C12-PN-AzPyC ${ }_{2} \mathrm{H}_{5}^{+} 12 \mathrm{~K}$. Both $\mathrm{Rg}_{\mathrm{g}}$ and $\mathrm{R}_{\mathrm{h}}$ are significantly larger than the corresponding neutral polymer nanoparticles, but their ratio is not affected, implying that the overall core-shell morphology of the particles is preserved. The $\mathrm{N}_{\mathrm{agg}}$ of the C12-PN-AzPyC${ }_{2} \mathrm{H}_{5}^{+} 12 \mathrm{~K}$ micelles decreases slightly, compared to C12-PN-AzPy12K.

\section{3 pH-dependent photophysical properties of C12-PN-AzPy nanoparticles in water $\left(15^{\circ} \mathrm{C}\right)$.}

(a)

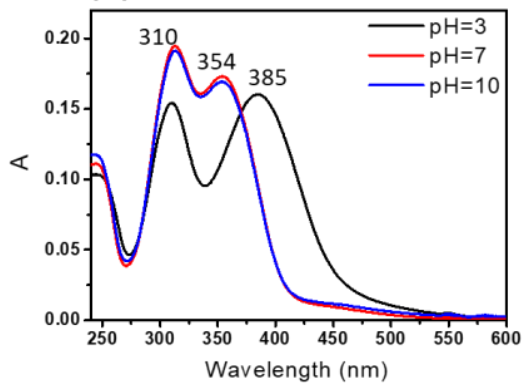

(b)

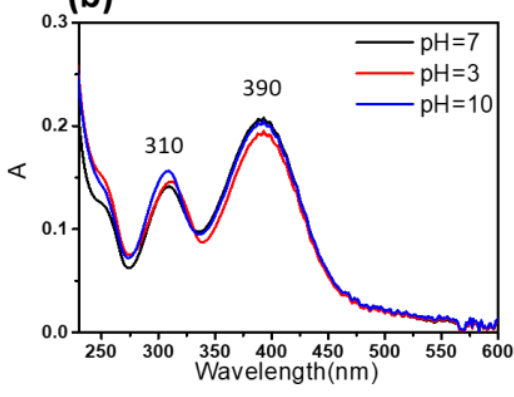

Figure 3. UV-vis spectra of (a), C12-PN-AzPy $7 \mathrm{~K}(0.1 \mathrm{mg} / \mathrm{mL})$ and (b), C12-PN-AzPyC $\mathrm{C}_{2} \mathrm{H}_{5}^{+}$ $(0.2 \mathrm{mg} / \mathrm{mL})$ under different $\mathrm{pH}$ values (temperature $\left.15^{\circ} \mathrm{C}\right)$.

UV-vis absorption spectrum of aqueous C12-PN-AzPy $7 \mathrm{~K}$ solutions $(0.1 \mathrm{mg} / \mathrm{mL}, \mathrm{pH} 3,7,10$. 
Since the pKa of AzPy is $\sim 4.53,{ }^{39}$ spectra recorded for solutions of $\mathrm{pH} 7$ and 10 correspond to the chromophore in its neutral form, while the spectrum measured at $\mathrm{pH} 3$ is characteristic of the azopyridinium protonated form. (Figure 3a). ${ }^{40,41}$ The UV spectra of solutions of C12-PN-AzPy $7 \mathrm{~K}$ of $\mathrm{pH} 7$ and 10 present a band at $354 \mathrm{~nm}$, characteristic of the $\pi-\pi^{*}$ transition of the transazopyridine group. This band undergoes a red shift from $354 \mathrm{~nm}$ to $385 \mathrm{~nm}$ upon protonation of the pyridine group at $\mathrm{pH} 3$. The red shift results from the strong push-pull electronic redistribution from the oxygen atom of the alkoxy substituent to the positively charged nitrogen atom of the azopyridium group. Similarly, the UV-vis spectra of aqueous $\mathrm{C} 12-\mathrm{PN}-\mathrm{AzPyC}_{2} \mathrm{H}_{5}{ }^{+}$solutions, presented in Figure 3b, have a band at $390 \mathrm{~nm}$, independently of the solution $\mathrm{pH}$, as expected since the N-ethyl-pyridinium group is not $\mathrm{pH}$-responsive ${ }^{6,42}$ The UV-Vis spectra of all samples (Figure 3a) have an additional band centered at $310 \mathrm{~nm}$ attributed to the $\pi$ - $\pi^{*}$ transition of the thiocarbonyl group linked to the $\omega$-chain end. ${ }^{43}$ It will not be included in the following discussions since the thiocarbonyl chromophore is inert at all $\mathrm{pH}$ values under the irradiation conditions used here. We confirmed by ${ }^{1} \mathrm{H}$ NMR spectroscopy that the ester that links the azopyridine group to the polymer main chain is not hydrolysed when the polymers are kept at $\mathrm{pH} 3$ or 10 for up to 5 days at room temperature and $\sim 1$ day when heated to $70{ }^{\circ} \mathrm{C}$. (Figure S13, S14.)

(a)

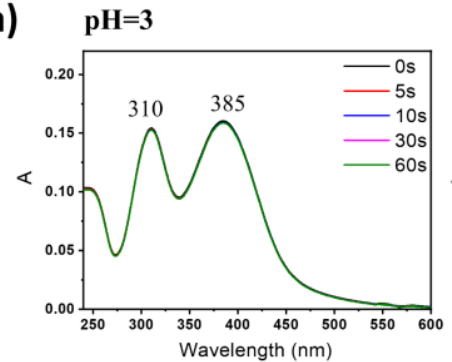

(b)

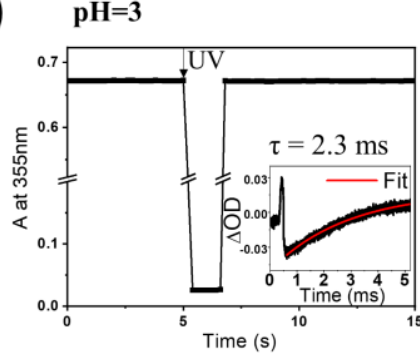

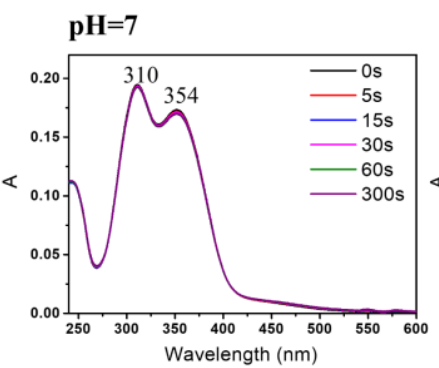
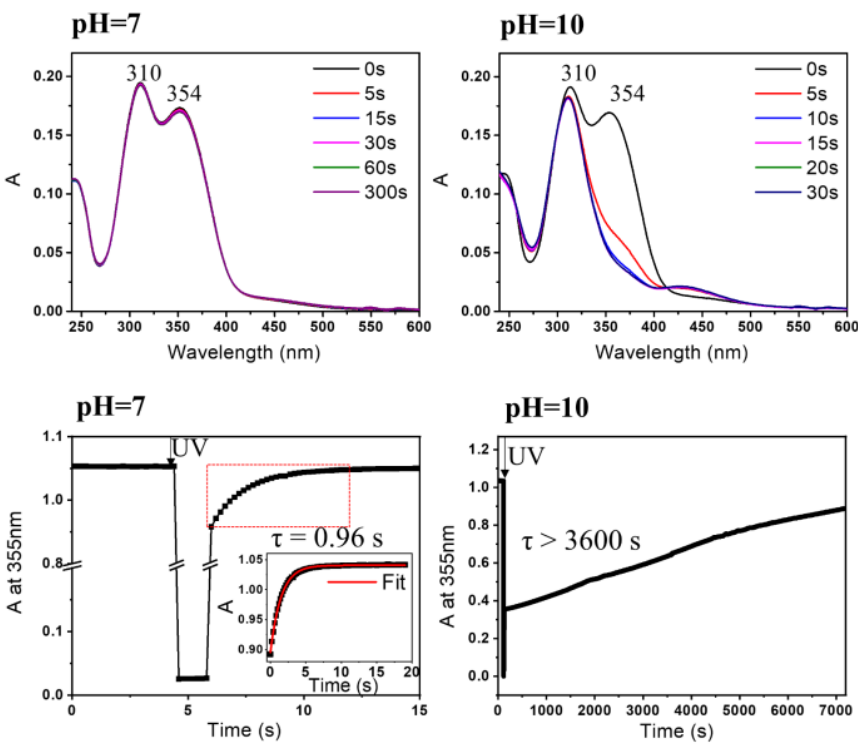

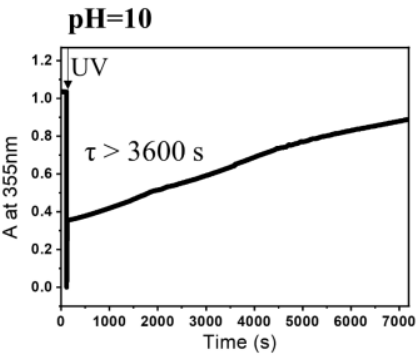

Figure 4. (a) UV-vis absorption spectra of C12-PN-AzPy $7 \mathrm{~K}$ aqueous solutions $(0.1 \mathrm{mg} / \mathrm{mL}, \mathrm{pH}$ $=3.0,7.0,10.0)$ upon irradiation at $365 \mathrm{~nm}$; (LED-UV lamp, $50 \mathrm{~mW} / \mathrm{cm}^{2}$, temperature: $15^{\circ} \mathrm{C}$ ); (b) transient absorption monitored at $355 \mathrm{~nm}$ of the same samples irradiated for $2 \mathrm{~s}$ at $365 \mathrm{~nm}$ 
Aqueous solutions of C12-PN-AzPy 7K in water ( $\mathrm{pH} \mathrm{3,} \mathrm{7,} \mathrm{and} \mathrm{10)} \mathrm{were} \mathrm{irradiated} \mathrm{at} 365 \mathrm{~nm}$ for 60 $\mathrm{s}$ and monitored by UV-vis absorption spectroscopy (Figure 4a). The UV-vis absorption spectrum of the polymer solution at $\mathrm{pH} 3$ does not change throughout the irradiation time. Transient absorption measurements indicate that the relaxation rate is extremely fast $(\tau=2.3 \mathrm{~ms}$, Figure 4 $\mathrm{pH}=3$, inset) so that the absorption spectrum of the cis-isomer cannot be detected by steady state absorption measurements. Similarly, transient absorption data recorded with the quaternized sample C12-PN-AzPyC $2 \mathrm{H}_{5}{ }^{+}$yielded a half-lifetime value of $2.1 \mathrm{~ms}$ for the cis-isomer (Figure S15). These data are in full agreement with the known characteristics of the cis-to-trans isomerization of quaternized azopyridine. ${ }^{6} \quad$ A schematic representation of a C12-PN-AzPyH ${ }^{+}$micelle is drawn in Scheme 2 (left). The micelle contains a hydrophobic core formed by closely-packed $n$-dodecyl chains surrounded by a shell of hydrated PNIPAM chains. The AzPyH ${ }^{+}$moieties are expected to be located near the water/micelle interface in view of their hydrophilicity.

The UV-vis absorption spectrum of the C12-PN-AzPy $7 \mathrm{~K}$ solution at $\mathrm{pH} 7$, where the azopyridine is in its neutral form, does not change, even after extended irradiation times (up to 300 s). Transient measurements indicate that the thermal cis-to-trans relaxation half-life is $\sim 0.96 \mathrm{~s}$ (Figure 4b, pH=7, inset), (stretched exponential function, Eq 5, experimental section). Based on previous studies of neutral AzPy, the fast back relaxation is an indication that the AzPy nitrogen forms H-bonds with available H-donors. Within the C12-PN-AzPy nanoparticle environment, the abundant amide groups of the PNIPAM chains can readily form H-bounds with the azopyridine nitrogen. To test this hypothesis, we measured the ${ }^{1} \mathrm{H}$ NMR spectrum of a physical mixture of PNIPAM homopolymer and CTA-AzPy ( $5 \mathrm{~mol} \%)$ in $\mathrm{CDCl}_{3}$ prepared by evaporation of a solution of PNIPAM and CTA-AzPy in tetrahydrofuran (THF) and subsequent dilution in $\mathrm{CDCl}_{3} .{ }^{44}$ The signals of the aromatic protons of the azopyridine groups exhibit downshifts in the presence of PNIPAM, from $8.77 \mathrm{ppm}$ to $8.84 \mathrm{ppm}$ for proton a and from $7.68 \mathrm{ppm}$ to $7.93 \mathrm{ppm}$ for proton $\mathbf{b}$ (Figure 5b). The observed shifts are indicative of the delocalization of the $\pi$ electrons of the azopyridine group. Moreover, the aromatic signals are broader in the spectrum of the mixed solution, compared to the original CTA spectrum (Figure 5a). The broadening of the NMR signals indicates a decrease of the CTA mobility, which is consistent with the coupling of the azopyridine to the PNIPAM chain via hydrogen bonding. ${ }^{45}$ 


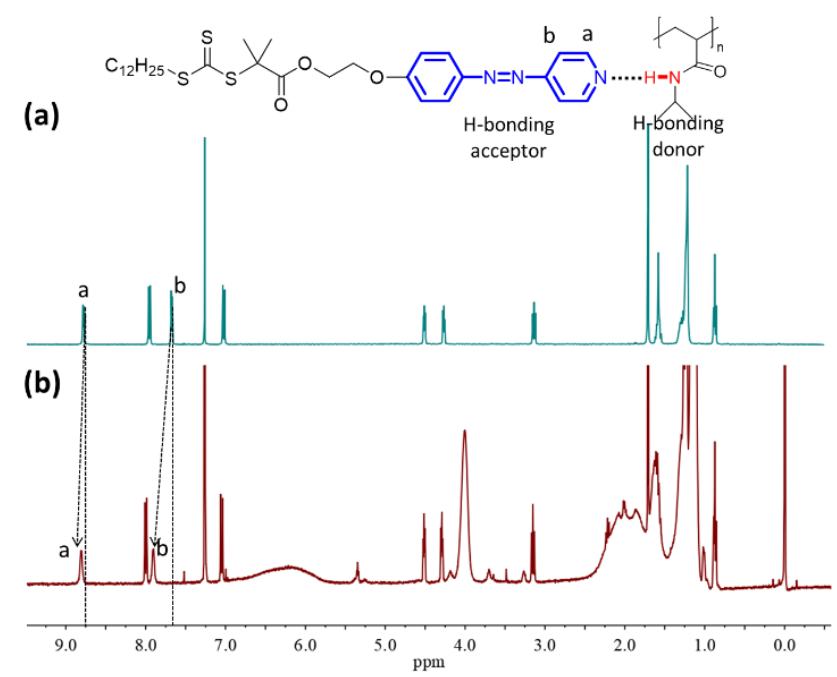

Figure 5. ${ }^{1} \mathrm{H}$ NMR spectra of (a), CTA-AzPy and (b), a supermolecular mixture of PNIPAM and CTA-AzPy. Solvent $\mathrm{CDCl}_{3}$.

We measured the FTIR spectrum of an intimate solid mixture of PNIPAM and CTA to gain further evidence of the occurrence of H-bonds between the CTA and the PNIPAM amides. The bands ascribed to N-H vibrations in the FTIR spectrum of the mixture (Figure 6) were fitted to the sum of three bands: a band at $3455 \mathrm{~cm}^{-1}$ attributed to the stretching vibration of free N-H bonds, a band around $3286 \mathrm{~cm}^{-1}$, indicative of the presence of hydrogen bonded N-H bonds, and a band at 3294 $\mathrm{cm}^{-1}$. The bands at $3455 \mathrm{~cm}^{-1}$ and $~ 3300 \mathrm{~cm}^{-1}$ are observed also in the spectrum of PNIPAM. We attribute the additional band at $3294 \mathrm{~cm}^{1}$ to the stretching vibration of $\mathrm{N}-\mathrm{H}$ hydrogen-bonded to the azopyridine nitrogen (Figure 6b). ${ }^{46-48}$

(a)

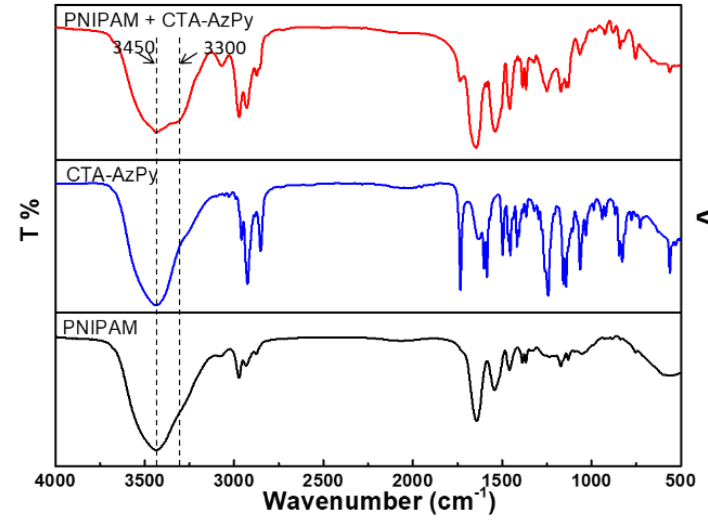

(b)

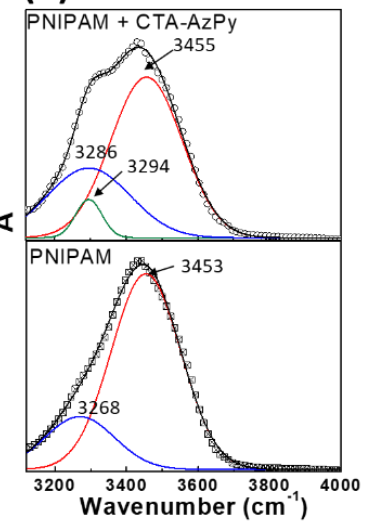

Figure 6. FTIR spectra of (a), PNIPAM (bottom black curve); CTA-AzPy (middle, blue trace) and a mixture of PNIPAM and CTA-AzPy (top, red trace); (b) fitting of the N-H stretching frequency region of the FTIR spectra of PNIPAM homopolymer and the PNIPAM/CTA mixture. 
The morphology of a C12-PN-AzPy 7K micelle in neutral aqueous solutions (Scheme 2, middle) consists of an n-dodecyl core surrounded by AzPy groups confined in a restricted environment through H-bond to PNIPAM chains, possibly close to the core in view of their hydrophobicity and the limited hydration of the PNIPAM chains confined close to the core. ${ }^{49}$

The UV-VIS absorption spectrum of C12-PN-AzPy 7K in a pH 10 aqueous environment undergoes significant changes upon irradiation of the sample: the band at $350 \mathrm{~nm}$ attributed to the $\pi-\pi^{*}$ transition decreases rapidly, while the band at $430 \mathrm{~nm}$ attributed to $\mathrm{n}-\pi^{*}$ transition grows in. The thermal cis-to-trans isomerization takes over 2 hours (Figure $\mathbf{4 b}, \mathrm{pH}=10$ ), which is typical of neutral azopyridine in which the nitrogen electronic doublet is retained. Indeed, the electron-rich azopyridine nitrogen is unlikely to form hydrogen bonds with hydroxyl anions known to be strong H-bonds acceptor ${ }^{52,53}$ and can interact with the amide hydrogen of the PNIPAM repeat unit. We measured the cis-to-trans thermal relaxation time of C12-PN-Azobenzene nanoparticles in water of $\mathrm{pH}$ 10. This polymer is a good model of C12-PN-AzPy in terms of self-assembly characteristics but the azobenzene end group is unable to form H-bounds. Its relaxation time in water is similar to that of C12-PN-AzPy in an alkaline environment (Figure S16).

These photophysical properties, together with the LS results described above, lead us to conclude that C12-PN-AzPy micelles in an pH 10 medium also adopt a core shell morphology. The precise morphology of the micelles cannot be ascertained from the data obtained so far. Further characterization by SANS or SAXS is needed to determine if the AzPy groups cluster within the micelle core or clustered in the vicinity of the core, as shown in Scheme 2 (right). 


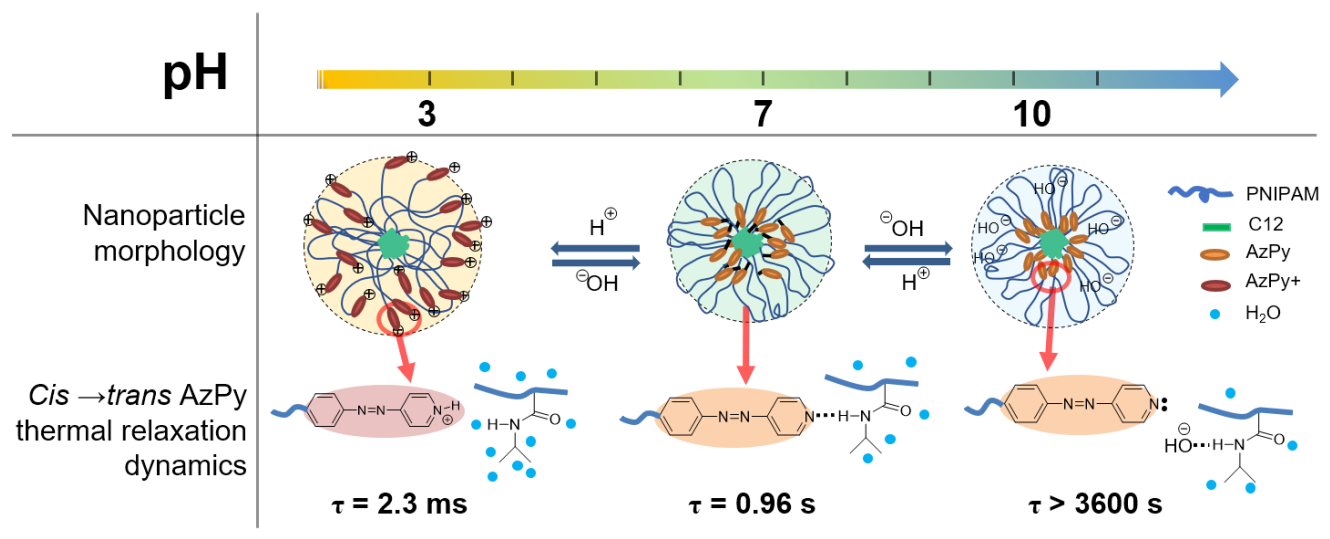

Scheme 2. Schematic representation of C12-PN-AzPy nanoparticles dispersed in water of $\mathrm{pH} 3,7$, and 10 based on data from LS, FTIR and ${ }^{1} \mathrm{H}$ NMR measurements and on the kinetics of the cis-to-trans thermal relaxation of azopyridine.

\section{Conclusion.}

When an amphiphilic copolymer is placed in contact with water, the hydrophobic moieties try to minimize contact with water and self-assemble. The segregation of the hydrophobic and hydrophilic components can be mitigated by attractive interactions between the two components through dipoledipole interactions or hydrogen-bonds. ${ }^{50}$ The balance of the opposite effects determines the morphology of the copolymer micelles. Routine physico-chemical micelles characterization methods often fail to detect inter-components complexation. The phenomenon can reveal itself through the emergence of unique macroscopic properties, as reported recently in a study of polylactide-b-poly(-2-isopropyl-2-oxazoline) micelles in water. In the course of this study of azopyridine-end modified poly(N-isopropylacrylamides) dispersed in neutral aqueous media, we recorded an exceptionally fast cis-to-trans thermal relaxation of the chromophore attributed to the formation of H-bonds between AzPy and PNIPAM chains. The "flower micelle" morphology typical of $\alpha, \omega$-hydrophobically-modified PNIPAMs cannot account for this observation. We postulate a micelle morphology consisting of a core of segregated hydrophobes linked to one chain end. The other type of hydrophobes are distributed throughout the micelle PNIPAM shell. Their location within the shell depends on the $\mathrm{pH}$ of the aqueous environment. This unique morphology is responsible for the fast photo-response of the chromophore and its sensitivity to the environment $\mathrm{pH}$. 


\section{Acknowledgments}

This work was supported in part by the scholarship from China Scholarship Council (CSC) under the Grant CSC No.201606880016. FMW acknowledges the Natural Sciences and Engineering Research Council of Canada for partial support of this work. We thank Prof. Haifeng Yu (Peking University) and Dr Xuewei Zhang (University of Montreal) for helpful discussion, Drs P. M. Aguiar and C. Malveau (University of Montreal) for their help in running NMR diffusion experiments, and Dr F. Tao (Shaanxi Normal University) for his help for the TEM imaging. H. Ren especially wishes to thank his family for their support over the years.

\section{Supporting information}

Supporting information including the synthesis and characterization of RAFT agents and end functional PNIPAMs as well as the characterization of the self-assembly structure, hydrolysis tests and UV-responsive properties of end functionalized PNIPAMs. 


\section{References}

(1). Jochum, F. D.; Theato, P. Temperature- and light-responsive smart polymer materials. Chem. Soc. Rev., 2013, 42, 7468-83.

(2). Trenor, S. R.; Shultz, A. R.; Love, B. J.; Long, T. E. Coumarins in Polymers: From Light Harvesting to Photo-Cross-Linkable Tissue Scaffolds. Chem. Rev., 2004, 104, 3059-3078.

(3). Zhao, Y. Light-Responsive Block Copolymer Micelles. Macromolecules., 2012, 45, 3647-3657.

(4). Bandara, H. M.; Burdette, S. C. Photoisomerization in different classes of azobenzene. Chem. Soc. Rev., 2012, 41, 1809-25.

(5). Ren, H.; Chen, D.; Shi, Y.; Yu, H.; Fu, Z.; Yang, W. Charged End-Group Terminated Poly(Nisopropylacrylamide)-b-poly(carboxylic azo) with Unusual Thermoresponsive Behaviors. Macromolecules., 2018, 51, 3290-3298.

(6). Garcia-Amoro s, J.; Massad, W. A.; Nonell, S.; Velasco, D. Fast Isomerizing Methyl Iodide Azopyridinium Salts for Molecular Switches. Org. Lett., 2010, 12, 3514-3517.

(7). Bujak, K.; Orlikowska, H.; Małecki, J. G.; Schab-Balcerzak, E.; Bartkiewicz, S.; Bogucki, J.; Sobolewska, A.; Konieczkowska, J. Fast dark cis-trans isomerization of azopyridine derivatives in comparison to their azobenzene analogues: Experimental and computational study. Dyes Pigments., 2019, $160,654-662$.

(8). Ruokolainen, J.; Makinen, R.; Torkkeli, M.; Makela, T.; Serimaa, R.; Brinke, G.; Ikkala, O. Switching supramolecular polymeric materials with multiple length scales. Science., 1998, 280, 557-60. (9). Millaruelo, M.; Chinelatto, L. S.; Oriol, L.; Piñol, M.; Serrano, J.; Tejedor, R. M. Synthesis and Characterization of Supramolecular Polymeric Materials Containing Azopyridine Units. Macromol. Chem. Phys., 2006, 207, 2112-2120.

(10). Mallia, V. A.; Antharjanam, P. K. S.; Das, S. Synthesis and studies of some 4-substituted phenyl4' -azopyridine-containing hydrogen-bonded supramolecular mesogens. Liq. Cryst., 2003, 30, 135-141. (11). Cui, L.; Zhao, Y. Azopyridine Side Chain Polymers: An Efficient Way To Prepare Photoactive Liquid Crystalline Materials through Self-Assembly. Chem. Mater., 2004, 16, 2076-2082.

(12). Sun, S.; Lees, A. J.; Zavalij, P. Y. Highly Sensitive Luminescent Metal-Complex Receptors for Anions through Charge-Assisted Amide Hydrogen Bonding. Inorg. Chem., 2003, 42, 3445-3453.

(13). Liu, X.; Xie, L.; Lin, J.; Lin, R.; Zhang, J.; Chen, X. Flexible porous coordination polymers constructed from 1,2-bis(4-pyridyl)hydrazine via solvothermal in situ reduction of 4,4' -azopyridine. Dalton T., 2011, 40, 8549.

(14). Aoki, K.; Nakagawa, M.; Ichimura, K. Self-Assembly of Amphoteric Azopyridine Carboxylic Acids: Organized Structures and Macroscopic Organized Morphology Influenced by Heat, $\mathrm{pH}$ Change, and Light. J. Am. Chem. Soc., 2000, 122, 10997-11004.

(15). Zhang, H.; Hao, R.; Jackson, J. K.; Chiao, M.; Yu, H. Janus ultrathin film from multi-level selfassembly at air-water interfaces. Chem. Commun., 2014, 50, 14843-14846.

(16). Gelebart, A. H.; Jan Mulder, D.; Varga, M.; Konya, A.; Vantomme, G.; Meijer, E. W.; Selinger, R.

L. B.; Broer, D. J. Making waves in a photoactive polymer film. Nature., 2017, 546, 632-636.

(17). Shen, G.; Xue, G.; Cai, J.; Zou, G.; Li, Y.; Zhang, Q. Photo-induced reversible uniform to Janus shape change of vesicles composed of PNIPAM-b-PAzPy2. Soft Matter., 2013, 9, 2512. 
(18). Xue, G.; Chen, K.; Shen, G.; Wang, Z.; Zhang, Q.; Cai, J.; Li, Y. Phase-separation and photoresponse in binary azobenzene-containing polymer vesicles. Colloid. Surface. A., 2013, 436, 1007 1012.

(19). Han, K.; Su, W.; Zhong, M.; Yan, Q.; Luo, Y.; Zhang, Q.; Li, Y. Reversible Photocontrolled Swelling-Shrinking Behavior of Micron Vesicles Self-Assembled from Azopyridine-Containing Diblock Copolymer. Macromol. Rapid Comm., 2008, 29, 1866-1870.

(20). Lin, W.; Tsai, M.; Rajappa, R.; Kramer, R. H. Design of a Highly Bistable Photoswitchable Tethered Ligand for Rapid and Sustained Manipulation of Neurotransmission. J. Am. Chem. Soc., 2018, $140,7445-7448$.

(21). Jerca, V. V.; Jerca, F. A.; Rau, I.; Manea, A. M.; Vuluga, D. M.; Kajzar, F. Advances in understanding the photoresponsive behavior of azobenzenes substituted with strong electron withdrawing groups. Opt. Mater., 2015, 48, 160-164.

(22). Wei, J.; Yan, Z.; Lin, L.; Gu, J.; Feng, Z.; Yu, Y. Photo/pH dual-responsive behavior of azopyridine-containing copolymer vesicles. React. Funct. Polym., 2013, 73, 1009-1014.

(23). Han, K.; Su, W.; Zhong, M.; Yan, Q.; Luo, Y.; Zhang, Q.; Li, Y. Reversible Photocontrolled Swelling-Shrinking Behavior of Micron Vesicles Self-Assembled from Azopyridine-Containing Diblock Copolymer. Macromol. Rapid Comm., 2008, 29, 1866-1870.

(24). Liu, G.; Ji, W.; Feng, C. Installing Logic Gates to Multiresponsive Supramolecular Hydrogel Coassembled from Phenylalanine Amphiphile and Bis(pyridinyl) Derivative. Langmuir., 2015, 31, 71227128.

(25). Keddie, D. J.; Moad, G.; Rizzardo, E.; Thang, S. H. RAFT Agent Design and Synthesis. Macromolecules., 2012, 45, 5321-5342.

(26). Chen, Y.; Yu, H.; Zhang, L.; Yang, H.; Lu, Y. Photoresponsive liquid crystals based on halogen bonding of azopyridines. Chem. Commun., 2014, 50, 9647-9649.

(27). Mallia, V. A.; Antharjanam, P. K. S.; Das, S. Synthesis and studies of some 4-substituted phenyl4' -azopyridine-containing hydrogen-bonded supramolecular mesogens. Liq. Cryst., 2003, 30, 135-141. (28). Wang, X.; Wu, C. Light-Scattering Study of Coil-to-Globule Transition of a Poly(N -isopropylacrylamide) Chain in Deuterated Water. Macromolecules., 1999, 32, 4299-4301.

(29). Gelebart, A. H.; Jan Mulder, D.; Varga, M.; Konya, A.; Vantomme, G.; Meijer, E. W.; Selinger, R. L. B.; Broer, D. J. Making waves in a photoactive polymer film. Nature., 2017, 546, 632-636.

(30). Chen, Y.; Quan, M.; Yu, H.; Zhang, L.; Yang, H.; Lu, Y. Fabrication of nanofibres with azopyridine compounds in various acids and solvents. Rsc Adv., 2015, 5, 31219-31225.

(31). Koga, T.; Tanaka, F.; Motokawa, R.; Koizumi, S.; Winnik, F. M. Theoretical Modeling of Associated Structures in Aqueous Solutions of Hydrophobically Modified Telechelic PNIPAM Based on a Neutron Scattering Study. Macromolecules., 2008, 41, 9413-9422.

(32). Kujawa, P.; Segui, F.; Shaban, S.; Diab, C.; Okada, Y.; Tanaka, F.; Winnik, F. M. Impact of EndGroup Association and Main-Chain Hydration on the Thermosensitive Properties of Hydrophobically Modified Telechelic Poly(N-isopropylacrylamides) in Water. Macromolecules., 2006, 39, 341-348.

(33). Kujawa, P.; Tanaka, F.; Winnik, F. M. Temperature-Dependent Properties of Telechelic Hydrophobically Modified Poly(N-isopropylacrylamides) in Water: Evidence from Light Scattering and Fluorescence Spectroscopy for the Formation of Stable Mesoglobules at Elevated Temperatures. Macromolecules., 2006, 39, 3048-3055.

(34). Kokufuta, E.; Ogawa, K.; Doi, R.; Kikuchi, R.; Farinato, R. S. Geometrical Characteristics of Polyelectrolyte Nanogel Particles and Their Polyelectrolyte Complexes Studied by Dynamic and Static 
Light Scattering $\dagger$. The Journal of Physical Chemistry B., 2007, 111, 8634-8640.

(35). Yang, F.; Cao, Z.; Wang, G. Micellar assembly of a photo- and temperature-responsive amphiphilic block copolymer for controlled release. Polym. Chem., 2015, 6, 7995-8002.

(36). Yao, C.; Wang, X.; Liu, G.; Hu, J.; Liu, S. Distinct Morphological Transitions of Photoreactive and Thermoresponsive Vesicles for Controlled Release and Nanoreactors. Macromolecules., 2016, 49, 82828295 .

(37). Greenspan, P.; Mayer, E. P.; Fowler, S. D. Nile red: a selective fluorescent stain for intracellular lipid droplets. J. Cell Biol., 1985, 100, 965-73.

(38). Greenspan, P.; Fowler, S. D. Spectrofluorometric studies of the lipid probe, nile red. J. Lipid Res., 1985, 26, 781-9.

(39). Buncel, E.; Keum, S. Studies of azo and azoxy dyestuffs-16 Investigations of the protonation and tautomeric equilibria of 4-(p'-hydroxyphenylazo)pyridine and related substrates. Tetrahedron., 1983, 39, 1091-1101.

(40). Willcock, H.; O'Reilly, R. K. End group removal and modification of RAFT polymers. Polym. Chem., 2010, 1, 149-157.

(41). Skrabania, K.; Miasnikova, A.; Bivigou-Koumba, A. M.; Zehm, D.; Laschewsky, A. Examining the UV-vis absorption of RAFT chain transfer agents and their use for polymer analysis. Polym. Chem.Uk., 2011, 2, 2074.

(42). Garcia-Amoros, J.; Velasco, D. Recent advances towards azobenzene-based light-driven real-time information-transmitting materials. Beilstein J. Org. Chem., 2012, 8, 1003-1017.

(43). Skrabania, K.; Miasnikova, A.; Bivigou-Koumba, A. M.; Zehm, D.; Laschewsky, A. Examining the UV-vis absorption of RAFT chain transfer agents and their use for polymer analysis. Polym. Chem.Uk., 2011, 2, 2074.

(44). Yu, H.; Liu, H.; Kobayashi, T. Fabrication and Photoresponse of Supramolecular LiquidCrystalline Microparticles. Acs Appl. Mater. Inter., 2011, 3, 1333-1340.

(45). Bryant, R. G. The NMR time scale. J. Chem. Educ., 1983, 60, 933.

(46). Coleman, M. M.; Skrovanek, D. J.; Hu, J.; Painter, P. C. Hydrogen bonding in polymer blends. 1. FTIR studies of urethane-ether blends. Macromolecules., 1988, 21, 59-65.

(47). Laurence, C.; Brameld, K. A.; Graton, J.; Le Questel, J.; Renault, E. The pKBHX Database: Toward a Better Understanding of Hydrogen-Bond Basicity for Medicinal Chemists. J. Med. Chem., 2009, 52, 4073-4086.

(48). Yamada, T.; Ichino, T.; Hanyu, M.; Ninomiya, D.; Yanagihara, R.; Miyazawa, T.; Murashima, T. A novel intramolecular hydrogen bonding between a side-chain pyridine ring and an amide hydrogen of the peptide backbone in tripeptides containing the new amino acid, a , a -di(2-pyridyl)glycine. Org. Biomol. Chem., 2004, 2, 2335-2339.

(49). Koga, T.; Tanaka, F.; Motokawa, R.; Koizumi, S.; Winnik, F. M. Theoretical Modeling of Associated Structures in Aqueous Solutions of Hydrophobically Modified Telechelic PNIPAM Based on a Neutron Scattering Study. Macromolecules., 2008, 41, 9413-9422.

(50). Gavezzotti, A.; Filippini, G. Geometry of the Intermolecular X-H...Y (X, Y = N, O) Hydrogen Bond and the Calibration of Empirical Hydrogen-Bond Potentials. J. Phys. Chem., 1994, 98, 4831-4837.

(51). Pimentel, G. C.; Sederholm, C. H. Correlation of Infrared Stretching Frequencies and Hydrogen Bond Distances in Crystals. J. Chem. Phys., 1956, 24, 639-641.

(52). Abu-Dari, K.; Raymond, K. N.; Freyberg, D. P. The bihydroxide (H3O2-) anion. A very short, symmetric hydrogen bond. J. Am. Chem. Soc., 1979, 101, 3688-3689. 
(53). Tuckerman, M. E.; Marx, D.; Parrinello, M. The nature and transport mechanism of hydrated hydroxide ions in aqueous solution. Nature., 2002, 417, 925-929. 